\title{
Serum Cytokine Dependent Hematopoietic Cell Linker (CLNK) as a Predictor for the Duration of Illness in Type 2 Diabetes Mellitus.
}

Suhaer Zeki Al-Fadhel ${ }^{1}$, Nibras H. Abdulsada Al-Ghuraibawi ${ }^{2}$, Dunia M.

Mohammed Ali ${ }^{3}$, Hussein Kadhem Al-Hakeim ${ }^{4 *}$

${ }^{1}$ Department of Clinical Laboratory Science, College of Pharmacy, University of Kufa, Iraq. E-mail: suhairz.saeed@uokufa.edu.iq.

${ }^{2}$ Department of Pharmacology, College of Pharmacy, University of Kufa, Iraq. E-mail: nibrash.abdalsada@uokufa.edu.iq.

${ }^{3}$ Department of Biochemistry, College of Medicine, University of Kufa, Iraq. E-mail: duniam.mohammedali@uokufa.edu.iq.

${ }^{4}$ Department of Chemistry, College of Science, University of Kufa, Iraq. E-mail: headm2010@yahoo.com.

*: Corresponding author: Prof.Dr. Hussein Kadhem Al-Hakeim, Department of Chemistry, College of Science, University of Kufa, Iraq. E-mail: headm2010@yahoo.com. ORCID 0000-0001-6143-5196. 
Abstract

Type 2 diabetes mellitus (T2DM) is an endocrine illness associate with various changes in the immune system and adaptor protein levels. Cytokine dependent hematopoietic cell linker (CLNK) is an adapter protein that regulates immune receptor signaling and acts as a regulator of the receptor signaling of T-cells and natural killer T-cell. The role of CLNK in T2DM is not studied previously. In the present study, serum CLNK level was measured and correlated with some sociodemographic and insulin resistance (IR) parameters. This is achieved by performing measurement of CLNK and insulin parameters (glucose, insulin, and HbA1c in addition to the calculation of the functions of IR (HOMA2IR), insulin sensitivity (HOMA\%S), and beta-cell function (HOMA\%B)) in $60 \mathrm{~T} 2 \mathrm{DM}$ patients and 30 controls. The results indicated a significant increase $(\mathrm{p}=0.025)$ in serum CLNK in patients group in comparison with the controls. Multivariate generalized linear model (GLM) analysis revealed no significant effect of age, BMI, and sex on the CLNK level. The results of tests for between-subjects showed that the CLNK affects diagnosis significantly $\left(\mathrm{F}=7.445, \mathrm{p}=0.008\right.$, partial $\left.\eta^{2}=0.081\right)$ and its effect is approximately the same as the effect of insulin $\left(F=8.107, p=0.006\right.$, partial $\left.\eta^{2}=0.087\right)$. The correlation study showed a highly significant positive correlation between CLNK and the duration of disease (rho=0.420, $\mathrm{p}<0.001)$. It can be concluded that the increase CLNK in T2DM revealing the role of the adaptor proteins level in the nature of disease. Elevation of CLNK level may be used as a predictor for diabetes complications, which needs more investigations.

Keywords: Diabetes Mellitus, Insulin resistance, Cytokines, Adaptor proteins, CLNK.

\section{Introduction}

Diabetes mellitus (DM) is a prevalent disorder characterized by hyperglycemia and results from the interaction between environmental, genetic, and behavioral risk 
factors (Chen et al. 2012). DM is a major public health concern with a growing prevalence around the world. In 2017, it is estimated that there are 451 million people aged over 18 years with DM worldwide, which expected to reach 693 million by the year 2045 (Cho et al. 2018). It was estimated that almost half of all people living with DM are undiagnosed (Cho et al. 2018). In Iraq, the prevalence of DM had risen significantly from 19.58/1000 in the year 2000 to 42.27 in 2015 (Hussain and Lafta 2019). Diabetes is estimated to contribute to $11.3 \%$ of deaths globally (Saeedi et al. 2020). Type 2 DM (T2DM) is the most familiar form of DM described by insulin resistance (IR), hyperglycemia, relative insulin deficiency, and insensitivity (Olokoba et al. 2012). Insulin insensitivity is produced because of declining insulin production, IR, and final pancreatic beta-cell malfunction results in a diminished in glucose transportation into the adipocytes, myocytes, and hepatocytes (Cerf 2013). T2DM is related to chronic inflammation which can be attributed to innate immune system dysregulation and this is a potential link between diabetes and metabolic syndrome (Banerjee and Saxena 2014). T2DM is associated with chronic inflammation in addition to metabolic dysregulation and there is also a link between metabolism and inflammation (Karstoft and Pedersen 2016). Chronic inflammation may be the cause and result of $\mathrm{T} 2 \mathrm{DM}$, and its related complications as an imbalance between proinflammatory and anti-inflammatory cytokines can affect immune functions (Naidoo et al. 2018). Therefore, the study of another biomarker for inflammation in T2DM is important to diagnose and treat low-grade inflammation (LGI) which is responsible for most diabetic complications (Eftekharian et al. 2016; van Diepen et al. 2017). For example, Previous investigations have broadly revealed the relationship of high C-reactive protein (CRP) levels with IR and progression of T2DM (Phosat et al. 2017). While interleukine (IL)-6 plays an exceptional role in the development of T2DM 
and elevated TNF- $\alpha$ levels over time could be a potential predictor of T2DM over time (Lainampetch et al. 2019). In addition to cytokines released in response to several stimuli and immune system dysregulation (Banerjee and Saxena 2012), adaptor proteins are another type, which is a very important constituent of signaling transduction systems both beyond and within the immune system (Verma et al. 2020). Adaptor proteins are molecular platforms that other proteins are accumulated on which (Verma et al. 2020). These adapter proteins control signaling by stabilizing or constraining molecular interactions essential for suitable activation of enzyme and for implementing these key effector molecules correctly inside the cell (Jordan and Koretzky 2010). Many adaptors are expressed in a variety of hematopoietic cell types (Dong et al. 2009; Jordan et al. 2003). The term "hematopoietic cells" describes all mature cell types and their immature precursors, or hematopoietic stem cells, in the blood. Examples of hematopoietic cells include, but are not limited to, hematopoietic stem cells, basophilic myelocytes, basophils, B-cells, etc.(Yu et al. 2018). Cytokine dependent hematopoietic cell linker (CLNK) is a type of adaptor protein Src homology 2 (SH2) domain-containing leukocyte protein of $76 \mathrm{kDa}$ (SLP-76) which exist in many lineages of hematopoietic cells including neutrophils, mast cells, macrophages, platelets, T-cells, and natural killer (NK) cells (Jordan and Koretzky 2010). CLNK has been reported to be spoken in cytokine-dependent cell lines of both lymphoid as well as myeloid in addition to some mast cell lines (Goitsuka et al. 2000). Although it can be distinguished in any type of cell, its expression appears to be strictly dependent on continual exposure to cytokines such as IL-2 and IL-3 (Ishihara and Hirano 2002). Furthermore, the temporary expression of CLNK results in increased immune-receptor signaling events in T-cells that are activated by cytokines (Cao et al. 1999). CLNK can act as a modulator to limit extreme NK cell activation in the proceeded stage of immune 
reactions anywhere teeming cytokines are out there (Hidano et al. 2008). NK cells are inhabitant cells of adipose tissue and they have numerous immune regulatory capacities including the release of immunoregulatory cytokines (IL-4 and IL-10), prompt dendritic cells, and expanding the recurrence of T regulatory cells. NK cells number are decreased in obese persond, proposing their contribution in local and sytemic inflammation in obesity (Tard et al. 2015). Obesity leads to IR which is the main feature for the etiology and pathogenesis of T2DM (Rehman and Akash 2016) that is found to be caused by activated immune-inflammatory pathway (Khodabandehloo et al. 2016) as the pro-inflammatory molecules are responsible of the activation of a variety of kinases in IR state (Hameed et al. 2015). There was no study deals with the role of CLNK in T2DM disease. Therefore, the aim of the present study is to examine the role of CLNK in the T2DM as a possible inflammatory marker or a potential predictor for some sociodemographic parameters and IR state parameters.

\section{Subjects and methods}

\section{Subjects}

The case-control study involved 60 T2DM patients and 30 healthy controls age and sex-matched. The samples were obtained from Al-Sadder Hospital in Najaf Governorate-Iraq from December 2019 to the end of January 2020. T2DM patients were diagnosed according to the World Health Organisation criteria (WHO 2006). They were assessed by full medical history by the physicians. All subjects were non-smokers. All subjects were fasted for at least 12 hours before the aspiration of blood in the morning. All the patients were on one tablet $(5 \mathrm{mg})$ of glibenclamide drugs daily. The control group was confirmed to be normal by clinical and biochemical tests. Written informed consent was taken from all subjects before participation in the current 
study. All procedures were under the established ethical standards. Approval for the study was obtained from the IRB of the University of Kufa (411/2019), which complies with the International Guidelines for Human Research protection as required by the Declaration of Helsinki, The Belmont Report, and International Conference on Harmonization in Good Clinical Practice (ICH-GCP).

Exclusion criteria: The present study excluded patients who satisfied the following criteria: patients with serum $\mathrm{FBG}>25 \mathrm{mmol} / \mathrm{L}$ and fasting insulin $>57.6$ mIU/L based on HOMA calculator software requirements, and patients with evident major diabetic complications, such as heart diseases, liver disease, and renal diseases. We also excluded patients who are receiving metformin and patients with albumin/creatinine ration above $30 \mathrm{mg} / \mathrm{g}$. This exclusion is based on previously mentioned facts (Al-Hakeim and Abdulzahra 2015) that patients using metformin cannot be used for insulin sensitivity studies because of the well-known effect of metformin on IR (Sangeeta 2012) and insulin sensitivity (Pernicova and Korbonits 2014). Serum CRP titer was negative in all samples i.e. less than $6 \mathrm{mg} / \mathrm{L}$. CRP test was used to exclude inflammation that causes changes in the acute phase reactant proteins.

\section{Methods}

Five milliliters of venous blood samples were drawn from patients and controls. After complete clotting, the blood was centrifuged $3000 \mathrm{rpm}$ for $10 \mathrm{~min}$, and then serum was separated to be stored at $-80 \mathrm{C}$ until analyzed. Commercial ELISA sandwich kits were used to measure serum insulin (DRG ${ }^{\circledR}$ International Inc., USA) and CLNK (Bioassay Technology Laboratory ${ }^{\circledR}$, China). Fasting serum glucose was measured spectrophotometrically by an enzymatic method (endpoint) using ready for use kit supplied by Biolabo® Co., France. HbA1c percentage in the whole blood was 
determined by ichroma ${ }^{\mathrm{TM}} \mathrm{HbA} 1 \mathrm{c}$ is a fluorescence Immunoassay (FIA) for the quantitative determination HbA1c. Serum CRP was measured using a kit supplied by Spinreact $^{\circledR}$, Spain. The test is based on the principle of latex agglutination. Anthropometric measurements weight and height were taken and BMI was calculated by weight in kilograms divided by square of height in meters.

Insulin sensitivity percentage (HOMA\%S), percentage of beta-cell function (HOMA\%B), and IR HOMA2IR were measured from fasting insulin and serum glucose by HOMA2 Calculator downloaded from (https://wwwdtuoxacuk/homacalculator/).

\subsection{Statistical analysis}

The distribution types of the variables' results were examined using the Shapiro-Wilk test as a normal statistical distribution. The results were expressed as (mean \pm standard deviation) or median (interquartile range). A Chi-square test was used for comparison between nominal variables. The pooled t-test has been used for the comparison between the patients and control groups and among subdivided groups in the measured parameters. Mann-Whitney U test was used for comparison between nonparametric variables. Pearson's correlation coefficients (r) or Spearman's correlation coefficient (rho, $\rho$ ) were used to evaluating the relationships among parameters. We used multivariate general linear model (GLM) analysis to delineate the associations between diagnosis (having T2DM or healthy control) and five biomarkers (CLNK, HOMA\%B, Insulin, HOMA2IR, and HOMA\%S). while controlling for confounding variables including age, BMI, and sex. Consequently, we carried out tests for between-subject effects to delineate the associations between diagnosis and each of the biomarkers. The effect size was estimated using partial eta-squared values. We excluded the FBS and HbA1c from the multivariate GLM analysis because they already 
have a very high correlation with T2DM and will cause a big colinearity of the tests The difference between groups is considered as statistically different when $p<0.05$. All statistical analysis was performed using SPSS Statistics Version 25 (2017) by IBMUSA. While the figures constructed using the Excel program of Microsoft Office 2016.

\section{Results}

\section{Socio-demographic and clinical characteristics}

The clinical and socio-demographic characteristics of the patients with T2DM and control groups are presented in Table 1. The results are typical for T2DM patients where there is a significant increase $(\mathrm{p}<0.001)$ in FBS, HbA1c, and HOMA2IR $(\mathrm{p}=0.031)$, while the secretion of insulin is significantly decreased $(\mathrm{p}=0.008)$ along with HOMA2\%B $(p<0.001)$. While HOMA2\%S showed no significance between the two groups. Serum CLNK was significantly elevated $(\mathrm{p}=0.025)$ in patients group in comparison with the control group.

\section{Multivariate GLM analysis}

The data were analyzed by multivariate generalized linear model (GLM) analysis with the biomarkers (HOMA\%B, Insulin, HOMA2IR, HOMA\%S, and CLNK) as dependent variables and diagnosis and the covariates (age, BMI, and sex) as an explanatory variable to examine their effect on the measured parameters were shown in Table 2. We found a highly significant effect of diagnosis $(\mathrm{F}=25.048, \mathrm{p}<0.001)$ on the measured parameters with a big effect size of $60.7 \%$, while age, BMI, and sex were not significant $(\mathrm{p}<0.05)$. We also examined the effects of measured parameters on the diagnosis by using tests for between-subjects. We found that the highest parameter that affects diagnosis significantly is HOMA\%B $\left(\mathrm{F}=30.14, \mathrm{p}<0.001\right.$, partial $\left.\eta^{2}=0.262\right)$, followed by HOMA2IR $\left(\mathrm{F}=13.164, \mathrm{p}<0.001\right.$, partial $\left.\eta^{2}=0.134\right)$, Insulin $(\mathrm{F}=8.107$, 
$\mathrm{p}=0.006$, partial $\left.\eta^{2}=0.087\right)$, and CLNK $\left(\mathrm{F}=7.445, \mathrm{p}=0.008\right.$, partial $\left.\eta^{2}=0.081\right)$. While HOMA $\% \mathrm{~S}$ has no significant effect on the diagnosis $(\mathrm{p}<0.05)$. These results indicated that diagnosis (i.e, being patients) have the same effects on the variation of serum CLNK or insulin levels.

\section{Correlation of $\mid$ CLNK with other parameters}

The result of the correlation study showed a highly significant positive correlation between CLNK and the duration of disease in the patients' group (rho=0.420, $\mathrm{p}<0.001$ ) as presented in Figure 1 . The results showed that $\mathrm{R}^{2}=0.1761$, which represents that $17.61 \%$ of the variance in the duration of illness is explained by serum CLNK level which is statistically significant $(\mathrm{p}<0.001)$. To obtain a better view of the dependence of CLNK level on the and duration of the illness, the duration of the disease is distributed into 5 years periods and the average of CLNK for each period was calculated and plotted in Figure 2. The figure presents the increase in the average serum CLNK with increasing the duration of disease. There is no significant correlation between serum CLNK and other parameters.

\section{Discussion}

The major finding of the present study is the increase in serum CLNK level in T2DM patients in comparison with the control group as presented in Table 1. Because of the lack of literature about the level of CLNK in the serum of T2DM patients, there is no simple explanation for this result. In the literature, only one research measured the serum CLNK in humans, namely in thalassemia patients (Al-Hakeim et al. 2019). The suggested explanation for the increase of CLNK in thalassemia patients in comparison with healthy controls depends on the reciprocal effects between immune 
system signaling and immature erythrocytes that release soluble receptors and signaling molecules including CLNK in the blood (Al-Hakeim et al. 2019). In our T2DM patients, the factor that may underpin the explanation of increased CLNK is via the LGI associated with T2DM disease (Burhans et al. 2018; Esser et al. 2014). The disease is started with chronic LGI associated obesity, which is involved in the development of IR that increases the risk of T2DM (McGill et al. 2008). When LGI is associated with lipid toxicity, together they appear to be major assaults on insulin sensitivity in insulinresponding tissues (Bilan et al. 2009). hyperinsulinemia also has a bidirectional relationship with chronic LGI, which may be developed into systemic inflammation and systemic inflammation causing IR and eventually compensatory hyperinsulinemia, which increases oxidative stress and inflammation processes (van den Oever et al. 2010). Therefore, it is confirmed that T2DM associated with LGI, IR, and obesity that interact with each other in a multidirectional mechanism (Badawi et al. 2010; Kang et al. 2016). For example, there is strong evidence that activation of inflammatory pathways interferes with normal metabolism and disrupts proper insulin signaling resulting in increased expression of pro-inflammatory cytokines (Gregor and Hotamisligil 2011). These cytokines can attach to their receptors on the cell membrane and produce an inflammatory reaction and exacerbating IR (Solinas et al. 2007). chronic activation of immune-inflammatory pathways lead to IR, thus rising risk of T2DM (Kan et al. 2013). IR development is generally correlated with pro-inflammatory cytokines-dependent LGI responses in various tissues (Fève and Bastard 2009). These cytokines eventually prevent the activation of insulin signaling receptors in $\beta$-cells islets (Rehman and Akash 2016) by activating kinases that phosphorylate serine residues of insulin receptor substrate and causes suppression of insulin signaling (Aroor et al. 2013). IR could be produced by altered recruitment of downstream adaptor 
proteins that CLNK belongs to (Siragusa and Fisslthaler 2017). The CLNK homology adaptor protein SLP-76 interacts physically with signaling molecules, the serine/threonine kinase HPK1(Homeodomain-interacting protein kinase-1) (Jordan et al. 2003), which may cause IR by affecting the insulin sensitivity by modifying the insulin receptors.

The other part that should be confirmed is the correlation between CLNK and inflammation. It is noticed previously that CLNK, as an adaptor protein, plays a crucial role in the T-cell signaling pathway mediated by the T-cell receptor, which is necessary for the adaptive immune response and important for differentiation, proliferation, and cytokine secretion ( $\mathrm{Ji}$ et al. 2015). It is expressed exclusively in cytokine-stimulated hemopoietic cells, including IL-2-induced T cells and NK cells, and IL-3-induced myeloid cells and mast cells (Boomer and Tan 2005).

Another important finding of the present study is the strong association between CLNK and the duration of T2DM illness. The strongest association comes from the finding that CLNK regulates the IFN- $\gamma$ production by different immune cells (Sasanuma et al. 2006). CLNK expression in NK cells is needed to improve the subsequent acquired immune responses. At the advanced stage of immune responses, CLNK can restrict excessive NK-cell activation, where abundant cytokines upregulate CLNK expression in NK cells. Since CLNK is needed for complete activation of NKT cells at such an advanced stage of immune responses, activated NKT cells expressing CLNK produce high amounts of cytokines includingIL-4and IFN- $\pi$ which can ultimately decide the nature of the subsequent acquired immune responses (Sasanuma et al. 2006).

Figure 1 showed the dependence of the duration of illness $(17.61 \%$ variation change) on the serum CLNK level. This result recalls a certain change in T2DM patients 
that depends on the period of illness. The duration of diabetes reflects the course of the disease (Gupta et al. 2017) and patients with longer illness duration have more complications (Akujuru et al. 2020). Another set of researchers found an association between the duration of diseases and the development of immune system concentrations. In glycemic controlled patients without complications, it is found a significant negative correlation between duration of disease with monocyte RANTES and a significant correlation with various types of neutrophil Toll-like receptors. The nature of correlation (negative or positive) depends on the type of Toll-like receptor, degree of glycemic control, and the presence of complications (Gupta et al. 2017). The duration of diabetes mellitus affects the concentration of IL-1 $\beta$ in both types of diabetes (Amin et al. 2020). Diabetes duration showed strong negative correlations with serum level of brain-derived neurotrophic factor (BDNF) (Li et al. 2016), and vitamin D3 (Aljack et al. 2019; Kishore and Code 2017). These changes with time indicating continuous deterioration of immune system defense with the duration of illness.

The CLNK level increases with the duration of T2DM as seen in Figure 2. The long duration of the disease leads to more complications (Hsu et al. 2015). Many diabetes complications appear with the progress of disease and correlated with the duration of disease including coronary artery diseases, nephropathy, retinopathy, and neuropathy (Kobayashi et al. 2020). As the duration of disease prolonged, the serum level of many biomarkers including uric and microalbuminuria (Latif et al. 2017) indicating the progression of nephropathy with time. Therefore, this is a good point to consider CLNK as a predictor for a complication that needs more investigation.

Another explanation of the increase of CLNK in T2DM with time through the mutual correlation of CLNK and duration of disease with platelet counts and properties. CLNK as an adaptor protein has a role in the activation of platelets (Senis et al. 2014). 
Moreover, the duration of illness in T2DM patients achieved a significant positive correlation with platelet count and volume (Biadgo et al. 2016). Collagen-induced platelet aggregation and granule release are markedly impaired in the absence of SLP76,.(Clements et al. 1999). These data revealed that SLP-76 expression is required for optimal receptor-mediated signal transduction in platelets as well as $\mathrm{T}$ lymphocytes (Clements et al. 1999). The overall of these results underpins a connection between CLNK, platelets, and duration of diabetes.

\section{Conclusion}

The present work is the first report about increase CLNK in T2DM revealing the role of the adaptor protein level in the disease naturally. The level of serum CLNK is strongly associated with the duration of illness and not associated with the IR parameters. As the prolonged duration of the disease leads to the development of diabetes complications and deterioration of the immune system, the elevation of the CLNK level may be used as a predictor for diabetes complications, which needs more investigations.

\section{Limitations of the Study}

The first limitation is the relatively small sample size. The second limitation is the restricted criteria in choosing the subjects of the study. All subjects were nonsmokers, and the patients were free of obvious complications and on one type of treatment (glibenclamide). These criteria are useful in removing the cofounders affecting the CLNK level but they are ideal and do not represent the real-life state.

\section{Acknowledgment}

None 


\section{Conflict of interest}

The authors declare that there is no conflict of interest .

\section{Funding}

There was no specific funding for this specific study.

\section{Author's contributions}

All the contributing authors have participated in the preparation of the manuscript.

\section{References}

Akujuru EE, Aprioku JS, Okerengwo AA (2020) Circulatory levels of pro-inflammatory cytokines (IL-6 and IL-1B) and neutrophil-lymphocyte ratio (NLR) in diabetic patients in Nigerian population Comparative Clinical Pathology 29:539-545 doi:10.1007/s00580-01903086-8

Al-Hakeim HK, Abdulzahra MS (2015) Correlation Between Glycated Hemoglobin and Homa Indices in Type 2 Diabetes Mellitus: Prediction of Beta-Cell Function from Glycated Hemoglobin/Korelacija Između Glikoliziranog Hemoglobina I Homa Indeksa U Dijabetes Melitusu Tipa 2: Predviđanje Funkcije Beta Ćelija Na Osnovu Glikoliziranog Hemoglobina Journal of medical biochemistry 34:191-199

Al-Hakeim HK, Al-Mayali HH, Maes M (2019) Cytokine Dependent Hematopoietic Cell Linker (CLNK) is Highly Elevated in Blood Transfusion Dependent Beta-Thalassemia Major Patients Available at SSRN 3369783

Aljack HA, Abdalla MK, Idris OF, Ismail AM (2019) Vitamin D deficiency increases risk of nephropathy and cardiovascular diseases in Type 2 diabetes mellitus patients Journal of research in medical sciences: the official journal of Isfahan University of Medical Sciences 24

Amin K, Qadr SH, Hussein RH, Ali KM, Rahman HS (2020) Levels of cytokines and GADA in type I and II diabetic patients Primary care diabetes 14:61-67

Aroor AR, McKarns S, DeMarco VG, Jia G, Sowers JR (2013) Maladaptive immune and inflammatory pathways lead to cardiovascular insulin resistance Metabolism 62:15431552

Badawi A, Klip A, Haddad P, Cole DE, Bailo BG, El-Sohemy A, Karmali M (2010) Type 2 diabetes mellitus and inflammation: Prospects for biomarkers of risk and nutritional intervention Diabetes Metab Syndr Obes 3:173-186 doi:10.2147/dmsott.s9089 
Banerjee M, Saxena M (2012) Interleukin-1 (IL-1) family of cytokines: role in type 2 diabetes Clinica chimica acta 413:1163-1170

Banerjee M, Saxena M (2014) Genetic polymorphisms of cytokine genes in type 2 diabetes mellitus World journal of diabetes 5:493

Biadgo B, Melku M, Abebe SM, Abebe M (2016) Hematological indices and their correlation with fasting blood glucose level and anthropometric measurements in type 2 diabetes mellitus patients in Gondar, Northwest Ethiopia Diabetes Metab Syndr Obes 9:91-99 doi:10.2147/DMSO.S97563

Bilan PJ, Samokhvalov V, Koshkina A, Schertzer JD, Samaan MC, Klip A (2009) Direct and macrophage-mediated actions of fatty acids causing insulin resistance in muscle cells Archives of physiology and biochemistry 115:176-190 doi:10.1080/13813450903079314

Boomer JS, Tan TH (2005) Functional interactions of HPK1 with adaptor proteins Journal of cellular biochemistry 95:34-44

Burhans MS, Hagman DK, Kuzma JN, Schmidt KA, Kratz M (2018) Contribution of Adipose Tissue Inflammation to the Development of Type 2 Diabetes Mellitus Comprehensive Physiology 9:1-58 doi:10.1002/cphy.c170040

Cao MY, Davidson D, Yu J, Latour S, Veillette A (1999) Clnk, a novel SLP-76-related adaptor molecule expressed in cytokine-stimulated hemopoietic cells The Journal of experimental medicine 190:1527-1534

Cerf ME (2013) Beta cell dysfunction and insulin resistance Front Endocrinol (Lausanne) 4:3737 doi:10.3389/fendo.2013.00037

Chen L, Magliano DJ, Zimmet PZ (2012) The worldwide epidemiology of type 2 diabetes mellitus - present and future perspectives Nature reviews endocrinology 8:228-236

Cho NH, Shaw JE, Karuranga S, Huang Y, da Rocha Fernandes JD, Ohlrogge AW, Malanda B (2018) IDF Diabetes Atlas: Global estimates of diabetes prevalence for 2017 and projections for 2045 Diabetes research and clinical practice 138:271-281 doi:10.1016/j.diabres.2018.02.023

Clements JL et al. (1999) Fetal hemorrhage and platelet dysfunction in SLP-76-deficient mice The Journal of clinical investigation 103:19-25

Dong Z, Cruz-Munoz M-E, Zhong M-C, Chen R, Latour S, Veillette A (2009) Essential function for SAP family adaptors in the surveillance of hematopoietic cells by natural killer cells Nature immunology 10:973

Eftekharian MM, Karimi J, Safe M, Sadeghian A, Borzooei S, Siahpoushi E (2016) Investigation of the correlation between some immune system and biochemical indicators in patients with type 2 diabetes Human antibodies 24:25-31

Esser N, Legrand-Poels S, Piette J, Scheen AJ, Paquot N (2014) Inflammation as a link between obesity, metabolic syndrome and type 2 diabetes Diabetes research and clinical practice 105:141-150 doi:10.1016/j.diabres.2014.04.006

Fève B, Bastard J-P (2009) The role of interleukins in insulin resistance and type 2 diabetes mellitus Nature Reviews Endocrinology 5:305

Goitsuka R et al. (2000) A BASH/SLP-76-related adaptor protein MIST/Clnk involved in IgE receptor-mediated mast cell degranulation International immunology 12:573-580

Gregor MF, Hotamisligil GS (2011) Inflammatory mechanisms in obesity Annual review of immunology 29:415-445 doi:10.1146/annurev-immunol-031210-101322

Gupta S, Maratha A, Siednienko J, Natarajan A, Gajanayake T, Hoashi S, Miggin S (2017) Analysis of inflammatory cytokine and TLR expression levels in Type 2 Diabetes with complications Scientific reports 7:7633 doi:10.1038/s41598-017-07230-8

Hameed I, Masoodi SR, Mir SA, Nabi M, Ghazanfar K, Ganai BA (2015) Type 2 diabetes mellitus: From a metabolic disorder to an inflammatory condition World journal of diabetes 6:598 
Hidano $S$ et al. (2008) Distinct regulatory functions of SLP-76 and MIST in NK cell cytotoxicity and IFN- $\gamma$ production International immunology 20:345-352

Hsu HY, Chiu HY, Lin HT, Su FC, Lu CH, Kuo LC (2015) Impacts of elevated glycaemic haemoglobin and disease duration on the sensorimotor control of hands in diabetes patients Diabetes/metabolism research and reviews 31:385-394 doi:10.1002/dmrr.2623

Hussain AM, Lafta RK (2019) Burden of non-communicable diseases in Iraq after the 2003 war Saudi medical journal 40:72-78 doi:10.15537/smj.2019.1.23463

Ishihara K, Hirano T (2002) Molecular basis of the cell specificity of cytokine action Biochimica et Biophysica Acta (BBA)-Molecular Cell Research 1592:281-296

Ji Q, Ding Y, Salomon AR (2015) SRC homology 2 domain-containing leukocyte phosphoprotein of $76 \mathrm{kDa}$ (SLP-76) N-terminal tyrosine residues regulate a dynamic signaling equilibrium involving feedback of proximal T-cell receptor (TCR) signaling Molecular \& Cellular Proteomics 14:30-40

Jordan MS, Koretzky GA (2010) Coordination of receptor signaling in multiple hematopoietic cell lineages by the adaptor protein SLP-76 Cold Spring Harb Perspect Biol 2:a002501a002501 doi:10.1101/cshperspect.a002501

Jordan MS, Singer AL, Koretzky GA (2003) Adaptors as central mediators of signal transduction in immune cells Nature immunology 4:110-116

Kan C, Silva N, Golden SH, Rajala U, Timonen M, Stahl D, Ismail K (2013) A systematic review and meta-analysis of the association between depression and insulin resistance Diabetes care 36:480-489

Kang YE et al. (2016) The Roles of Adipokines, Proinflammatory Cytokines, and Adipose Tissue Macrophages in Obesity-Associated Insulin Resistance in Modest Obesity and Early Metabolic Dysfunction PLoS One 11:e0154003-e0154003 doi:10.1371/journal.pone.0154003

Karstoft K, Pedersen BK (2016) Exercise and type 2 diabetes: focus on metabolism and inflammation Immunology and cell biology 94:146-150 doi:10.1038/icb.2015.101

Khodabandehloo H, Gorgani-Firuzjaee S, Panahi G, Meshkani R (2016) Molecular and cellular mechanisms linking inflammation to insulin resistance and $\beta$-cell dysfunction Translational Research 167:228-256

Kishore PK, Code Q (2017) Association of vitamin D with insulin resistance in Type 2 Diabetic Mellitus patients International Journal of Biomedical Research 8:200-203

Kobayashi Y, Suzuki R, Yasukawa K, Oba K, Yamauchi T, Yatomi Y, Kadowaki T (2020) Oxidized albumin in blood reflects the severity of multiple vascular complications in diabetes mellitus Metabolism Open:100032 doi:https://doi.org/10.1016/j.metop.2020.100032

Lainampetch J et al. (2019) Association of Tumor Necrosis Factor Alpha, Interleukin 6, and CReactive Protein with the Risk of Developing Type 2 Diabetes: A Retrospective Cohort Study of Rural Thais J Diabetes Res 2019:9051929-9051929 doi:10.1155/2019/9051929

Latif H, Iqbal A, Rathore R, Butt NF (2017) Correlation between Serum Uric Acid Level and Microalbuminuria in Type-2 Diabetic Nephropathy Pakistan journal of medical sciences 33:1371-1375 doi:10.12669/pjms.336.13224

Li B, Lang N, Cheng Z-F (2016) Serum Levels of Brain-Derived Neurotrophic Factor Are Associated with Diabetes Risk, Complications, and Obesity: a Cohort Study from Chinese Patients with Type 2 Diabetes Molecular Neurobiology 53:5492-5499 doi:10.1007/s12035-015-9461-2

McGill AT, Stewart JM, Lithander FE, Strik CM, Poppitt SD (2008) Relationships of low serum vitamin D3 with anthropometry and markers of the metabolic syndrome and diabetes in overweight and obesity Nutrition journal 7:4 doi:10.1186/1475-2891-7-4 
Naidoo V, Naidoo M, Ghai M (2018) Cell- and tissue-specific epigenetic changes associated with chronic inflammation in insulin resistance and type 2 diabetes mellitus Scandinavian journal of immunology 88:e12723 doi:10.1111/sji.12723

Olokoba AB, Obateru OA, Olokoba LB (2012) Type 2 diabetes mellitus: a review of current trends Oman Med J 27:269-273 doi:10.5001/omj.2012.68

Pernicova I, Korbonits M (2014) Metformin-mode of action and clinical implications for diabetes and cancer Nature Reviews Endocrinology 10:143

Phosat C et al. (2017) Elevated C-reactive protein, interleukin 6, tumor necrosis factor alpha and glycemic load associated with type 2 diabetes mellitus in rural Thais: a crosssectional study BMC endocrine disorders 17:44 doi:10.1186/s12902-017-0189-z

Rehman K, Akash MSH (2016) Mechanisms of inflammatory responses and development of insulin resistance: how are they interlinked? Journal of biomedical science 23:87

Saeedi P et al. (2020) Mortality attributable to diabetes in 20-79 years old adults, 2019 estimates: Results from the International Diabetes Federation Diabetes Atlas, 9(th) edition Diabetes research and clinical practice:108086 doi:10.1016/j.diabres.2020.108086

Sangeeta S (2012) Metformin and pioglitazone in polycystic ovarian syndrome: a comparative study The Journal of Obstetrics and Gynecology of India 62:551-556

Sasanuma $\mathrm{H}$ et al. (2006) Dual function for the adaptor MIST in IFN- $\gamma$ production by NK and CD4+ NKT cells regulated by the Src kinase Fgr Blood 107:3647-3655

Senis YA, Mazharian A, Mori J (2014) Src family kinases: at the forefront of platelet activation Blood, The Journal of the American Society of Hematology 124:2013-2024

Siragusa M, Fisslthaler B (2017) Insulin Keeps PYK-ing on eNOS: Enhanced Insulin Receptor Signaling Induces Endothelial Dysfunction. Am Heart Assoc,

Solinas G et al. (2007) JNK1 in hematopoietically derived cells contributes to diet-induced inflammation and insulin resistance without affecting obesity Cell metabolism 6:386397 doi:10.1016/j.cmet.2007.09.011

Tard C, Rouxel O, Lehuen A (2015) Regulatory role of natural killer T cells in diabetes biomedical journal 38:484-495

van den Oever IAM, Raterman HG, Nurmohamed MT, Simsek S (2010) Endothelial dysfunction, inflammation, and apoptosis in diabetes mellitus Mediators Inflamm 2010:792393792393 doi:10.1155/2010/792393

van Diepen JA et al. (2017) SUCNR1-mediated chemotaxis of macrophages aggravates obesityinduced inflammation and diabetes Diabetologia 60:1304-1313 doi:10.1007/s00125017-4261-z

Verma NK, Tran T, Kelleher D (2020) Adaptor Protein Regulation in Immune Signalling Front Immunol 11:441

WHO (2006) Definition and diagnosis of diabetes mellitus and intermediate hyperglycaemia: report of a WHO/IDF consultation

Yu J, Devine S, Caligiuri MA, He S (2018) Methods for mobilizing hematopoietic stem cells. Google Patents, 
Table 1: Socio-demographic, clinical, and biomarker data in T2DM patients as compared with healthy controls.

\begin{tabular}{|l|c|c|c|}
\hline Parameter & Control $(\mathrm{n}=30)$ & Patients $(\mathrm{n}=60)$ & $\mathrm{p}$-value \\
\hline Sex M/F & $20 / 10$ & $31 / 29$ & $0.176^{*}$ \\
\hline Age Year & $50.27 \pm 8.25$ & $53.08 \pm 7.85$ & 0.056 \\
\hline BMI kg/m2 & $26.90 \pm 2.54$ & $28.65 \pm 5.23$ & 0.088 \\
\hline Duration of illness Year & - & $7(3-11)$ & - \\
\hline HbA1c \% & $4.69 \pm 0.38$ & $8.57 \pm 2.06$ & $<0.001$ \\
\hline FBS mM & $5.20 \pm 0.29$ & $10.54 \pm 4.58$ & $<0.001$ \\
\hline Insulin pM & $88.57(52.26-122.96)$ & $73.53(35.99-103.91)$ & $0.008^{* *}$ \\
\hline HOMA2\%B & $103.30(79.25-124.25)$ & $42.70(19.8-72.20)$ & $<0.001^{* *}$ \\
\hline HOMA2\%S & $75.10(64.00-99.45)$ & $49.40(24.10-106.65)$ & $0.058^{* *}$ \\
\hline HOMA2IR & $1.33(0.99-1.56)$ & $2.09(0.94-4.15)$ & $0.031^{* *}$ \\
\hline CLNK ng/ml & $4.27(2.59-5.08)$ & $4.89(3.67-5.93)$ & $0.025^{* *}$ \\
\hline
\end{tabular}

-Results expressed as mean \pm SD or median (interquartile range).

*: Calculated by $\chi^{2}$, **: Calculated by Mann-Whitney U test, while other p-values were carried out by using pooled T-test. 
Abbreviations: FBS: Fasting blood sugar, BMI: Body mass index, HOMA2R: Homeostatic model assessment of insulin resistance, HOMA2\%B: Homeostatic model assessment of beta cells function percentage, HOMA2\%S: Homeostatic model assessment of insulin sensitivity percentage, CLNK: Cytokine Dependent Hematopoietic Cell Linker.

Table 2. Results of multivariate GLM analysis with the biomarkers as dependent variables and diagnosis as an explanatory variable while adjusting for extraneous variables.

\begin{tabular}{|c|c|c|c|c|c|c|}
\hline Tests & $\begin{array}{l}\text { Dependent } \\
\text { Parameters }\end{array}$ & $\begin{array}{l}\text { Explanatory } \\
\text { variables }\end{array}$ & $\mathrm{F}$ & df & $\mathrm{P}$ & $\begin{array}{c}\text { Partial } \\
\eta^{2}\end{array}$ \\
\hline \multirow{4}{*}{ Multivariate } & \multirow{4}{*}{$\begin{array}{l}\text { HOMA\%B, Insulin, } \\
\text { HOMA2IR, CLNK, } \\
\text { HOMA\%S. }\end{array}$} & Diagnosis & 25.048 & $5 / 81$ & $<0.001$ & 0.607 \\
\hline & & Sex & 0.735 & $5 / 81$ & 0.599 & 0.043 \\
\hline & & Age & 0.501 & $5 / 81$ & 0.774 & 0.030 \\
\hline & & BMI & 1.027 & $5 / 81$ & 0.408 & 0.060 \\
\hline \multirow{5}{*}{$\begin{array}{l}\text { Tests of Between- } \\
\text { Subjects Effects }\end{array}$} & HOMA\%B & Diagnosis & 30.140 & 1 & $<0.001$ & 0.262 \\
\hline & HOMA2IR & Diagnosis & 13.164 & 1 & $<0.001$ & 0.134 \\
\hline & Insulin & Diagnosis & 8.107 & 1 & 0.006 & 0.087 \\
\hline & CLNK & Diagnosis & 7.445 & 1 & 0.008 & 0.081 \\
\hline & HOMA\%S & Diagnosis & 0.056 & 1 & 0.601 & 0.003 \\
\hline
\end{tabular}


Abbreviations: BMI: Body mass index, HOMA2R: Homeostatic model assessment of insulin resistance, HOMA2\% B: Homeostatic model assessment of beta cells function percentage, HOMA2\%S: Homeostatic model assessment of insulin sensitivity percentage, CLNK: Cytokine dependent hematopoietic cell linker.

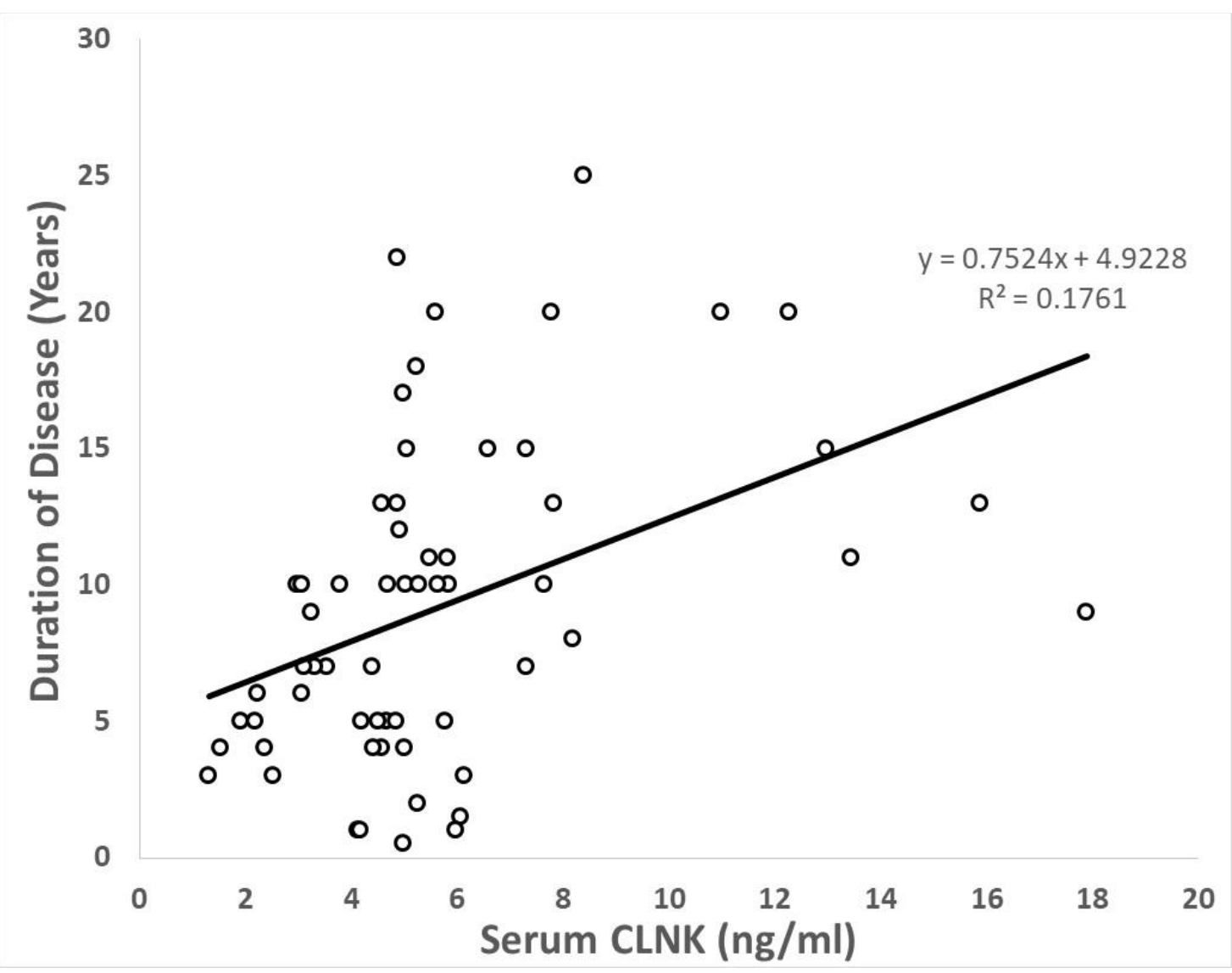

Figure 1. The correlation between CLNK and duration of disease in the T2DM patients' group. 


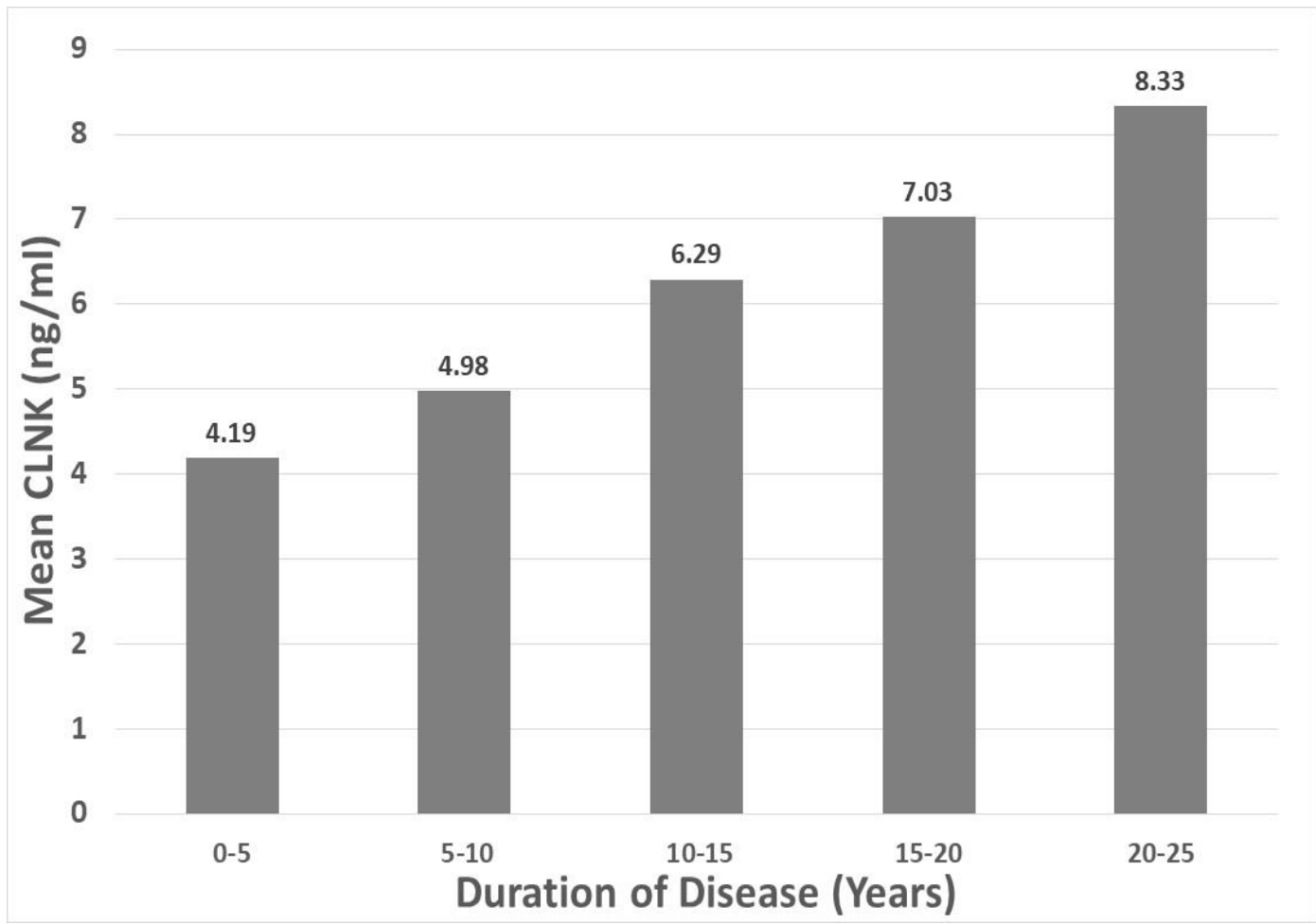

Figure 2. Distribution of mean CLNK according to the periods of the duration of T2DM disease. 